\title{
Knowledge of Obstetric Danger Signs and Associated Factors Among Pregnant Women Attending Antenatal Care Clinics in Jigjiga Public Health Institution, Somali, Ethiopia
}

\author{
Omar Mohamed Abdi ${ }^{1, ~ *, ~ M u k h t a r ~ S h e k a b d u l a h i ~ W a r s a m e ~}{ }^{2}$, Abdulahi Omar Abdulahi², \\ Faysal Harun Hassan ${ }^{3}$ \\ ${ }^{1}$ Independent Research and Humanitarian Activities Consultant, Jigjiga, Ethiopia \\ ${ }^{2}$ Department of Public Health, College of Medicine and Health Sciences, Jigjiga University, Jigjiga, Ethiopia \\ ${ }^{3}$ Department of Health Extension Worker, Jigjiga Health Science Collage, Jigjiga, Ethiopia
}

Email address:

faaruuqi33@hotmail.com (O. M. Abdi), muktarshek66@yahoo.com (M. S. Abdulahi), daga1779@gmail.com (A. O. Abdulahi), fh26029@gmail.com (F. H. Hassan)

${ }^{*}$ Corresponding author

\section{To cite this article:}

Omar Mohamed Abdi, Mukhtar Shekabdulahi Warsame, Abdulahi Omar Abdulahi, Faysal Harun Hassan. Knowledge of Obstetric Danger Signs and Associated Factors Among Pregnant Women Attending Antenatal Care Clinics in Jigjiga Public Health Institution, Somali, Ethiopia. Journal of Gynecology and Obstetrics. Vol. 8, No. 5, 2020, pp. 122-134. doi: 10.11648/j.jgo.20200805.11

Received: August 11, 2020; Accepted: August 22, 2020; Published: September 10, 2020

\begin{abstract}
Background: Pregnancy is a normal process that results in a series physiological and psychosocial changes that can be accompanied by some danger signs and complications which are potentially life threatening to the mother and/or foetus. Although, childbirth is positive expectation for most of the women, it can be problematic for others. Knowledge of obstetric danger sign is essential first step in accepting and for motivating women to seek health care service with appropriate and timely referral to comprehensive obstetric and new-born care. Objective: This study was aimed to assess knowledge of obstetric danger signs and associated factors among pregnant women attending ANC clinic in Jigjiga public health institution, Somali, Ethiopia, 2019. Method: Institutional based cross-sectional study design was conducted in Jigjiga Public Health institution from April 15 to 31, 2019. A Systematic random sampling technique was used to select a total of 399 study participants using single population proportion. Data was collected using a pre-tested and well-structured questionnaire. Data was coded, entered and cleaned in EpiData version 6.04 and then exported into SPSS statistical software version 20 for analysis. Descriptive statistics were used to determine sociodemographic, obstetric characteristic, health \& health related variables and knowledge of obstetric danger sign while bivariate \& multivariate logistic regression was used to identify factors associated with knowledge of obstetric danger signs. Result: Out of 399 Respondents, 164 (41.1\%) were knowledgeable regarding all type of obstetric danger sign during Pregnancy, Childbirth and Postpartum; The most frequently key obstetric danger signs identified by participants were sever vaginal bleeding during the pregnancy $64.2 \%$, childbirth $57.4 \%$ and postpartum 50.4\%; Formal education [AOR: $2.297,95 \%$ CI $(1.274,4.143)$ ]; Antenatal care service visit [AOR: 4.226; 95\%CI $(2.256,7.918)]$; PNC utilization visit [AOR=5.256, 95\% CI $(2.879,9.595)$ ]; history of obstetric complication [AOR: $4.273 ; 95 \%$ CI $(2.042,8.944)$ ] and other related factors like Maternal Occupation, home visit, Mass media access and husbands a companion during health facility visit were statistically significance associated with being knowledgeable about obstetric danger signs. Conclusion and Recommendation: A significant proportion of pregnant women were not knowledgeable about obstetric danger signs at all categories which may result lack of delay in seeking health care service. Increasing level of awareness, health education, home to home visit and support women's health seeking behaviour and encouraging husband to support women's during health care visit may help women to recognize obstetric danger sign and seek health care services.
\end{abstract}

Keywords: Knowledge, Factor Associated, Obstetric Danger Sign, Pregnant Women, Key Obstetric Danger Sign During Pregnancy, Childbirth and Postpartum, Jigjiga, Somali, Ethiopia 


\section{Introduction}

Pregnancy is a normal process that results in a series physiological and psychosocial changes that can be accompanied by some danger signs and complications which are potentially life threatening to the mother and/or foetus. Although, childbirth is positive expectation for most of the women, it can be problematic for others [1]. Pregnancy is a very important event from both social and medical points of view; therefore, it should receive special care and attention from the family, community and health care system. The major goal of focused antenatal care is to help women maintain normal pregnancies through health promotion and disease prevention, early detection, recognition and management of obstetric danger signs [2].

Obstetric danger sign is one aspect of obstetric problem recognized by individual, family and community level that occur during pregnancy (such as vaginal bleeding, swollen hands/face, decreasing fetal movement and blurred vision); during child birth (severe vaginal bleeding, pro-longed labor, convulsions, and retained placenta) and during postpartum period (vaginal bleeding following child birth, loss of consciousness, and high fever) [3]. These danger signs are not the actual obstetric complications, but sign and symptoms that are easily identified by non-clinical personal [4].

Knowledge of key danger signs is essential primary step in accepting suitable and quick referral to obstetric care, or motivating women to seek skilled attendance at birth and uptaking of maternal waiting home with appropriate and timely referral to comprehensive obstetric \& newborn care service [5]. Delay in seeking care is one of the key factors leading to maternal and neonatal mortality, which associated with lack of knowledge of obstetric danger signs, It is therefore of vital importance that pregnant women and their families are aware of the danger signs of obstetric complications to enable them to respond appropriately to complications that may arises [6].

The identification of these danger signs and its relationship with complications during pregnancy would increase the capacity of women, their husband and families to seek for timely health care, following the appropriate steps to insure a safe birth and post-partum [7]. Haemorrhage followed by hypertension in pregnancy, abortion and sepsis are the leading causes of maternal deaths in Ethiopia, which can be averted through recognition of obstetric danger signs [8]. Poor knowledge of danger signs is a major contributor to delays in seeking obstetric care and hence to high maternal mortality and morbidity [9]. Most obstetrics complications that results in maternal deaths are unpredictable, and their onset can be sudden and severe. The complications can lead to maternal death without any warning during pregnancy and childbirth. The global Maternal mortality ratio (MMR) fell by nearly $44 \%$ over the past 25 years [10].

Maternal mortality remains a major public health challenge worldwide Globally, approximately 140 million births occur every year [11]. World Health Organization (WHO) estimates that, 287,000 women a year or every day
830 women die from complications related to pregnancy and childbirth. The majority of these (99\%) occur in developing countries and, out of those, $51 \%$ occur in the Sub-Saharan region [12] and still women die because of complications during and following pregnancy and childbirth [13]. Ethiopia has made notable progress in decreasing maternal mortality ratio from 676 in 2011 to 353 in 2015 per 100,000 live births [6]. Ethiopia has so far reduced maternal mortality by $69 \%$ from the 1990 s estimate with annual reduction rate of $5 \%$ or more [8]. According to 2016 Ethiopia Demographic Health Survey the pregnancy-related mortality ratio (PRMR) is 412 per 100,000 live births [14]. A study conducted at urban Tanzania revealed that obstetric danger signs of the can be prevented through pregnant mothers' knowledge on obstetric danger sign [15].

Women's knowledge about these obstetric danger signs during pregnancy, delivery and postpartum is still low in subSaharan African countries evidenced by studies conducted in Burkina Faso, Ethiopia [16, 17] and rural Tanzania [5]. Another study at rural Tanzania indicates that women with severe acute obstetric complications are often referred to hospitals and clinics in late stages of emergency due to delays that include lack of recognition of severity of maternal complications, lack of preparedness for an emergency, women's lack of decision-making power regarding prenatal care and place of delivery, and perception of inadequate or poor-quality hospital care. Barriers that prevent women from accessing hospitals are multiple and compounded. In Bangladesh, most of the births and maternal complications occur in the home in the absence of skilled attendants [18]. According to Ethiopian Democratic Health Survey in 2016, The number of reproductive age group received Antenatal care from skilled health providers were $62 \%$. The level of knowledge of obstetric danger sign in Somali region is very low, $15.5 \%$ in Erar Distract and $37.9 \%$ in Jigjiga City Administration [19, 21].

World Health Organization (WHO) recommends to raise awareness among women about danger signs before, during or after delivery to improve early detection of problems and reduce the delay to seek obstetric care [21]. Therefore, Antenatal care (ANC) provides a unique opportunity to strengthen knowledge of obstetric danger signs and encourage institutional delivery [22]. The national reproductive strategy of Ethiopia has given emphasis on the need to empower women, men, families and communities to recognize obstetric related risks at least $80 \%$ and to take responsibility for developing and implementing appropriate response [23].

Therefore, increasing mothers' knowledge is essential for reducing delayed seeking of health care, both individuals and communities to recognize pregnancy-related risks to react well once such problems occur [24]. Reduction of maternal mortality is a global priority and it is one of the sustainable development goals and the key to reducing maternal mortality ratio and improving maternal health by increasing attendance by skilled health personnel throughout pregnancy 
and delivery [25]. Recognizing obstetric danger is one of cornerstone for safe motherhood strategy whose objective is to promote the timely use of skilled maternal and neonatal care during pregnancy, childbirth and postpartum period [26]. Enough knowledge of obstetric danger signs is fundamental to mothers for proper uptake of maternal and new-born care services in the communities as well as at health facilities. On the other hand, poor knowledge of danger signs delays cares to seek and ultimately greater risk to death. Raising awareness for pregnant women to know these obstetric danger signs would improve early detection of problems and reduces the delay of seeking obstetric care [27].

Regardless of the Ethiopia national strategy and different contribution made on skill up women's knowledge of obstetric danger sign, There is no articles found in the study Somali region or few studies conducted in Ethiopia at large showing the magnitude and severity of the problem that encourage the concerned bodies to take remedial action [19, 20]. Therefore, The Objective of this study was to fill above mentioned gap by assessing the knowledge of obstetric danger sign and determining factors associated with knowledge of obstetric danger sign among pregnant mothers in Jigjiga public heath institution, Somali Regional State, Ethiopia, 2019.

\section{Methods and Materials}

\subsection{Study Area and Period}

This study was conducted from April 15 to 31, 2019, in public health institution in Jigjiga City, which is located eastern part of Ethiopia and it is the capital city of the Somali region, Ethiopia. It is located approximately $120 \mathrm{~km}$ western to the Harar and $635 \mathrm{~km}$ away from Addis Ababa (the capital city of Ethiopia). Jigjiga City has an elevation of $1609 \mathrm{~m}$ above the sea level. The climate of Jigjiga is semi-arid with the mountain climate, with hot and dry summers and cold winters. Jigjiga city has 20 urban kebeles and 10 rural kebeles. Based on figures from the central statistical agency in 2005, Jigjiga has an estimated total population of 98,076 of whom 50,355 are men and 47,721 are women.

SHHY referral specialized hospital and Karamara general hospital are the only hospitals in Jigjiga city providing care for 98,076 catchment population. There are other two public health center called Jigjiga $\mathrm{HC}$ and Ayardaga $\mathrm{HC}$ which offer
ANC service and other maternal health service packages.

\subsection{Study Design}

An institution based cross-sectional study design was applied to assess knowledge of obstetrics danger signs among the pregnant women attending Jigjiga public health institution.

\section{Population}

\section{Source Population}

All pregnant women attending ANC Clinic in public health institution of Jigjiga city was source population.

\section{Study Population}

A Randomly selected pregnant women who have attended ANC clinic in public health institution in Jigjiga city was study population.

\section{Inclusive/Exclusion Criteria}

\section{Inclusive Criteria}

Those pregnant women who have ANC attendant in Jigjiga City public Health Institution was included in this study.

Exclusive Criteria

Pregnant mothers who couldn't hear, speak and respond for questionnaire due to serious illness /mental problem were excluded from the study

\subsection{Sample Size Determination}

A sample size was obtained by determining the outcome variable and various factors significantly associated with knowledge of obstetric danger signs and associated factor. First and second specific objectives of the study was calculated separately using Statcalc of Epi Info with crosschecking manual calculation and the larger sample size was taken to use for this study. With consideration of $95 \%$ of level of Confidence, 5\% Margin of Error, $80 \%$ of Power, design effect of 1 and ratio of unexposed to exposed almost equivalent to $1: 1$ with assumption of prior study conducted in Somali, Ethiopia and Africa as shown below tables.

Sample size determination for the 1st Objective: Knowledge

The required sample size for this objective was obtained using single population proportion $\left.\left(n=(Z / 2)^{2} \mathrm{pq} / \mathrm{d}^{2}\right)\right)$ based on different studies with the following assumptions (in table 1). The Proportion of knowledge of obstetric danger was $37.9 \%$ according to the community-based study conducted in Jigjiga [21].

Table 1. Sample size calculation for the knowledge of obstetric danger signs for objective one.

\begin{tabular}{|c|c|c|c|c|}
\hline Knowledge of obstetric danger sign of all categorise & Year & Study Area & Calculated Sample Size & Reference \\
\hline $37.9 \%$ & 2018 & Jigjiga, Somali, Ethiopia & 362 & [21] \\
\hline $15.5 \%$ & 2016 & Erar, Somali, Ethiopia & 201 & [19] \\
\hline $37.9 \%$ & 2019 & Bahirdar, Amhara, Ethiopia & 362 & [28] \\
\hline $25.2 \%$ & 2017 & Chamwino district, Tanzania & 290 & [9]. \\
\hline
\end{tabular}

Sample size determination for 2nd objective: Factors

The sample size of the of the second objective was calculated using double population proportion of the factors associated with knowledge of obstetric danger sign from different study by using Epi Info statistical software version as summarized (in table 2). 
Table 2. Sample size calculation for different factors associated with obstetric danger signs.

\begin{tabular}{|c|c|c|c|c|c|c|}
\hline \multicolumn{3}{|c|}{ Factor associated with ODSs } & \multirow{2}{*}{ Year } & \multirow{2}{*}{ Study Area } & \multirow{2}{*}{$\begin{array}{l}\text { Calculated } \\
\text { Sample Size }\end{array}$} & \multirow{2}{*}{ Reference } \\
\hline Variables & Exposed & Unexposed & & & & \\
\hline Husband age & $40.9 \%$ & $14.9 \%$ & 2018 & Jigjiga, Somali & 109 & [21] \\
\hline ANC Utilisation & $70.4 \%$ & 29.6 & 2018 & Jigjiga, Somali & 20 & [21] \\
\hline Mass education & $54.5 \%$ & $17.7 \%$ & 2018 & Jigjiga, Somali & 62 & {$[21]$} \\
\hline Family size & $47.8 \%$ & $27.2 \%$ & 2018 & Jigjiga, Somali & 200 & [21] \\
\hline Household income & $64.2 \%$ & $35.8 \%$ & 2014 & Debre Berhan, Amhara & 122 & [29] \\
\hline Residence & 43,2 & 19.4 & 2016 & Erar, Somali & 137 & [19] \\
\hline
\end{tabular}

Summary of sample size for 1st and 2nd objectives

Comparing for the sample size constructed for both objectives based on the larger sample size, relevant to study areas and recent year conducted, the final sample size was calculated as discussed: Sample size (n)=1.962pq/d2. Where,

$\mathrm{p}=0.379$ (Knowledge of ODS in Jigjiga [21].

$\mathrm{q}=(1-\mathrm{p})=0.9$

$\mathrm{d}=0.05 \alpha=95 \%$ of confidence interval

The final calculated sample size of this study was 362 with adjusted compensation of non-response rate of $10 \%$, the final required sample was 399 pregnant women.

\section{Sampling techniques/procedure}

Sampling technique

All public Health Institution in Jigjiga town was drawn a sample study by using simple proportion to size and the required sample was allocated to each health institution proportional to their average number of ANC attendant for the 4th quarter ANC attendant of 2018. Hence, the total sample size of 399 , The sample size constructed in each health facilities was: 173, 118, 58 and 50 from SHY referral hospital, Karamara general hospital, Ayardaga health centre and Jigjiga health centre in Jigjiga city respectively.

Finally, A systematic random sampling technique was used to get pregnant women from the register at ANC clinic. Each clinic day of four health institution, at least 15 questionnaires was filled with the total number of attendants whereas the sampling interval determined using the expected client based on previous records or normal routine patient follow on waiting area. The first client is the one whose serial number was randomly selected by lottery method. Subsequent client was obtained by adding the day's sampling interval to the previous client's serial number until the required sample size was met.

\section{Sampling procedures}

As per below figure 1 it is discussed the schematic of sampling procedure to assess knowledge and associated factors of obstetric danger sign among the pregnancy women attending ANC in Jigjiga public health institution, 2019.

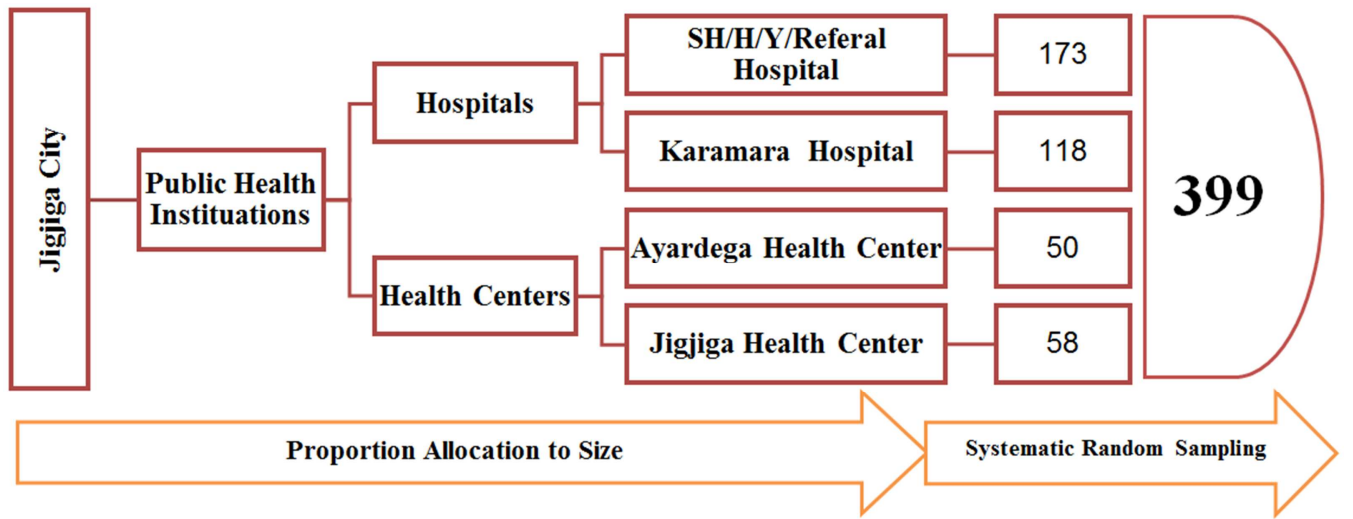

Figure 1. Schematic presentation of sampling procedure to assess knowledge and associated factors of obstetric danger sign among the pregnancy women attending ANC in Jigjiga public health institution, 2019.

\subsection{Study Variables}

In this study, different variables that address the objectives of the study were assessed.

Dependent variable

Knowledge of obstetric danger sign (knowledgeable/Not knowledgeable).

Independent variables

The independent variables in the study are regarded as the potential factors associated with knowledge of obstetric danger sign.

Socio demographic variables

1. Maternal age,
2. Husband age

3. Family size,

4. Occupation of the pregnancy women

5. Occupation of Husband,

6. Educational status of the pregnancy women

7. Educational status of the husband

8. Religion and

9. Ethnicity and

10. Family income

Obstetric characteristics

1. ANC follow up

2. PNC follow up

3. Institutional delivery 
4. Gravida

5. History of obstetric danger sign

Health and health related characteristics

1. Media access

2. Distance from health service

3. Home to home visit

4. Husband accompanying during visit

5. Final decision to seek health care

\subsection{Operational Definition}

Obstetric danger sign: Presence of condition that increases the chances of pregnant woman and/ or her unborn child dying or having poor health during pregnancy, Labour/delivery, postnatal until 6 weeks [6].

Knowledge: Knowledge of obstetric danger signs means the basic information that the mothers have regarding obstetric danger signs [3, 30].

Danger signs- are indications which can threat the life of the mother and/or foetus [30].

Key danger signs: are common, can easily be recognized $\&$ are signs of serious complications and they are grouped under three phases of pregnancy, childbirth \& postpartum [3, 30].

Obstetrics complication- It is complication occurred at the time of pregnancy, childbirth and postpartum that can be identified by health care provider [19].

Knowledgeable of obstetric danger sign: woman was considered as knowledgeable of obstetric danger sign if she can mention above the mean of sum of key danger of all categories [3, 28, 30].

Knowledgeable on key danger signs of pregnancy: In this study, a woman was considered as knowledgeable if she can mention at least two of three key danger signs of pregnancy $[3,28,30]$.

Knowledgeable on key danger signs of labour/childbirth: In this study, a woman was considered as knowledgeable if she can mention at least two of four key danger sig of Labor/childbirth spontaneously or after prompting [3, 28, 30].

Knowledgeable on key danger signs of postpartum: In this study, a woman was considered Knowledgeable if she can mention at least two of three key danger sign $\mathrm{s}$ for postpartum spontaneously or after prompting [3, 28, 30].

Data Quality Control

The questionnaire was developed after reviewing relevant literatures to include all the possible variables that address the objective of the study plus merit of referral WHO and John Hopkins Bloomberg School of Public health. The questionnaire first prepared in English and translate to Local language of Somali and then translated back to English to maintain consistency of the contents of the instrument.

To ensure quality of data, the data collection tool was pretested on $5 \%$ of the study subjects before the actual data collection in Kebribayah health centre (South of Jigjiga) and Tuliguled health centre (North and East of Jigjiga) which have similar sociodemographic status with study area of Jigjiga public health institution. The aim of the pre-test was to determine the methods, the feasibility, clarity of the questions, terms, effectiveness of instrument, duration required to complete each questionnaire. The questionnaire was modified based on the identified gaps during the pre-test. The completed questionnaires were checked every day during data collection for completeness, clarity and consistency by the supervisors and the principal investigator. Any error detected was corrected accordingly.

\subsection{Data Analysis Procedure}

The data was first coded, entered and cleaned in EpiData version 6.04 and then exported into SPSS statistical software version 20 for analysis. Frequencies and cross tabulations were used to check for missed values and variables. Frequencies, proportions and measures of central tendency was used to describe the characteristics of participants such as socio demographic, obstetric factors, health and health related information in table, figure as well as narrative note.

The key danger signs of pregnancy, childbirth and postpartum have been measured by considering knowledgeable if any if pregnancy women mention at least two of each category and lastly the above mean of all key danger sign of each category was considered as "Knowledgeable of obstetric danger signs". The model fitness was checked since the P-Value for Cox \& Snell R Square $(0.417)$ is greater than 0.05 so the model was well fitted.

Bi-variate logistic regression was used to determine the association between independent variables and the outcome variable. Variables in bivariate analysis whose $p$ value less than $0.25(\mathrm{p}<0.25)$ was included into Multivariate logistic regression. The strength of association between variables was determined using odds ratio, with $95 \%$ confidence interval. P-values of 0.05 or lower was taken to declare that the association is statistically significant.

\section{Ethical Consideration}

Ethical clearance was obtained from Ethical Review committee of school of graduate studies, Jigjiga University. Then permission to carry out the study was also obtained from corresponding hospital administration. After briefing the purpose and procedures of the study, all study subjects on pregnancy mother attending ANC clinic was asked based on their willingness. Participants 'right was respected to withdraw from the study at any time. All responses were kept confidential. Mother with danger sign of pregnancy during visit was advised to closely follow and maintain ANC visits.

\section{Result}

\subsection{Sociodemographic Characteristics}

All the 339 participants' who were present at the time of study responded (i.e., 100\% response rate).

The minimum and maximum age of participants were 18 and 41 years old respectively, with the mean age of $27.76 \pm$ 5.132 years. The age of most participants ranged from 25 to 29 years were $158(39.60 \%)$ whereas the minimum and maximum age of participant's husband were 18 and 59 years 
old respectively, with the mean age of $32.95 \pm 6.680$ years; Age group between 30 to 34 of 127 (31.83\%) were the most ranged.

Most of the participants were Somali 364 (91.23\%) followed by Amhara 19 (4.76\%) and Oromo 13 (2.75). The main religion of the participants was belonging to Muslim, $369(92.48 \%)$ With regards to their level of educational status of the participants, $186(46.62 \%)$ attended formal education of which $24.56 \%, 18.80 \%$ and $3.26 \%$ were attended primary, secondary and higher levels of education and the rest 213 $(53.4 \%)$ were illiterate. Similarly, their husband's level of educational status was asked \& $156(39.10 \%)$ were illiterate, and the remaining $243(60.9 \%)$ were attended formal education.

Out of 399 pregnant women participated in the study, around $185(46.37 \%)$ were housewives and $273(68.41 \%)$ of the husband were employed. an About 188 (47.12\%) of the family sized between Four to Six. About one-sixth of participants $64(16.04 \%)$ had a family monthly income of less than 500 ETB, while 74 (18.55\%) had 500-1000 ETB and only $261(65.41 \%)$ of participants had a monthly income more than 1000 ETB.

Table 3. Frequency distribution of selected socio-demographic characteristics of study participants of Jigjiga City, 2019.

\begin{tabular}{|c|c|c|c|c|}
\hline S. No & Variables & Category & Number & Percent \\
\hline \multirow{6}{*}{1} & \multirow{6}{*}{ Age of the Pregnant mother } & $15-19$ & 27 & 6.77 \\
\hline & & $20-24$ & 71 & 17.79 \\
\hline & & $25-29$ & 158 & 39.60 \\
\hline & & $30-34$ & 103 & 25.81 \\
\hline & & $35-39$ & 32 & 8.02 \\
\hline & & $>40$ & 8 & 2.01 \\
\hline \multirow{6}{*}{2} & \multirow{6}{*}{ Age of the father } & $15-19$ & 8 & 2.01 \\
\hline & & $20-24$ & 17 & 4.26 \\
\hline & & $25-29$ & 88 & 22.06 \\
\hline & & $30-34$ & 127 & 31.83 \\
\hline & & $35-39$ & 98 & 24.56 \\
\hline & & $>40$ & 61 & 15.29 \\
\hline \multirow{4}{*}{3} & \multirow{4}{*}{ Marital status } & Married & 390 & 97.7 \\
\hline & & Divorced & 5 & 1.3 \\
\hline & & Single & 2 & .5 \\
\hline & & Widowed & 2 & .5 \\
\hline \multirow{4}{*}{4} & \multirow{4}{*}{ Ethnicity } & Somali & 364 & 91.23 \\
\hline & & Amhara & 19 & 4.76 \\
\hline & & Oromo & 11 & 2.76 \\
\hline & & Others & 5 & 1.25 \\
\hline \multirow{4}{*}{5} & \multirow{4}{*}{ Religion } & Muslim & 369 & 92.48 \\
\hline & & Orthodox & 20 & 5.01 \\
\hline & & Other & 8 & 2.01 \\
\hline & & Protestant & 2 & 0.50 \\
\hline \multirow{4}{*}{6} & \multirow{4}{*}{ Education Mother } & Illiterate & 213 & 53.83 \\
\hline & & Elementary school $\left(1-8^{\text {th }}\right)$ & 98 & 24.56 \\
\hline & & Secondary school $\left(9-12^{\text {th }}\right)$ & 75 & 18.80 \\
\hline & & Above secondary school & 13 & 3.26 \\
\hline \multirow{5}{*}{7} & \multirow{5}{*}{ Occupation Mother } & Housewife & 185 & 46.37 \\
\hline & & Merchant & 134 & 33.58 \\
\hline & & Government employee & 52 & 13.03 \\
\hline & & Private Employee & 24 & 6.02 \\
\hline & & Others & 4 & 1.00 \\
\hline \multirow{4}{*}{8} & \multirow{4}{*}{ Education Husband } & Illiterate & 156 & 39.10 \\
\hline & & Elementary school $\left(1-8^{\text {th }}\right)$ & 89 & 22.31 \\
\hline & & Secondary school $\left(9-12^{\text {th }}\right)$ & 112 & 28.07 \\
\hline & & Above secondary school & 42 & 10.53 \\
\hline \multirow{5}{*}{9} & \multirow{5}{*}{ Occupation Husband } & 1. Government employee & 174 & 43.60 \\
\hline & & 2. Private employee & 99 & 24.81 \\
\hline & & 3. Merchant & 76 & 19.05 \\
\hline & & 4. Day labor & 31 & 7.76 \\
\hline & & 5. Others & 19 & 4.76 \\
\hline \multirow{3}{*}{10} & \multirow{3}{*}{ Household Number } & $<3$ & 91 & 22.81 \\
\hline & & $4--6$ & 188 & 47.12 \\
\hline & & $>7$ & 120 & 30.08 \\
\hline \multirow{3}{*}{11} & \multirow{3}{*}{$\begin{array}{l}\text { Estimated Monthly family income in } \\
\text { birr }\end{array}$} & $<500$ Birr & 64 & 16.04 \\
\hline & & 500-1000 Birr & 74 & 18.55 \\
\hline & & >1000 Birr & 261 & 65.41 \\
\hline
\end{tabular}




\subsection{Obstetric Characteristics of the Attendants}

Majority of the study participants 190 (47.62\%) had pregnancy more than five times), while around $76(19.05 \%)$ reported that they had a history of obstetric danger sign or complication. of the total of 399 pregnant women participated in this study, $245(61.40 \%)$ had a history of ANC Visit, and $136(34.08 \%)$ of the mother had institutional delivery while 169 (42.36\%) reported having PNC utilization visit.

Table 4. Frequency distribution of obstetrics characteristics of study participants of Jigjiga City, 2019.

\begin{tabular}{lllll}
\hline S. N & Variables & Category & Number & Percent \\
\hline \multirow{2}{*}{1} & \multirow{2}{*}{ Gravida } & G 1 & 62 & 15.54 \\
& & G 2-4 & 147 & 36.84 \\
\multirow{2}{*}{2} & \multirow{2}{*}{ ANC Visit } & G->5 & 190 & 47.62 \\
& & Yes & 245 & 61.40 \\
3 & PNC Visit & No & 154 & 38.59 \\
\multirow{2}{*}{4} & \multirow{2}{*}{ Health Facility Delivery } & Yes & 169 & 42.36 \\
& Ho & Yes & 136 & 37.64 \\
5 & History of Obstetric & Yes & 76 & 19.05 \\
\hline
\end{tabular}

\section{Health and Health Related Information}

Out of the 399 of study participants, 264 (66.16\%) heard about the obstetric danger sign of pregnancy, Childbirth and Postpartum. Regarding the source of information: Health Care Provider 118 (44.69\%) followed by Media 92 (34.84\%) was the most common source of information of obstetric danger sign while the sum of the Friend and Relative were 23 $(8.65 \%)$ were the least source of information. Among the participants $330(82.71 \%)$ had access for mass media for different types of media like Radio, TV and Mobile. A 287 (71.93\%) of the attendants reported that they can travel by foot to the nearest health facilities more than 30 minutes. Out of the 399 pregnancy women, only $105(26.3 \%)$ had been visited by HEWs or HWs on house to house visit. Regarding the final decision to seek care $256(64.16 \%)$ of the participants reach decision by themselves while $49(12.28 \%)$ of them their husband accompany during health facility visit in receiving obstetric health care service.

Table 5. Frequency distribution of health and health related service characteristic of study participants of Jigjiga City, 2019.

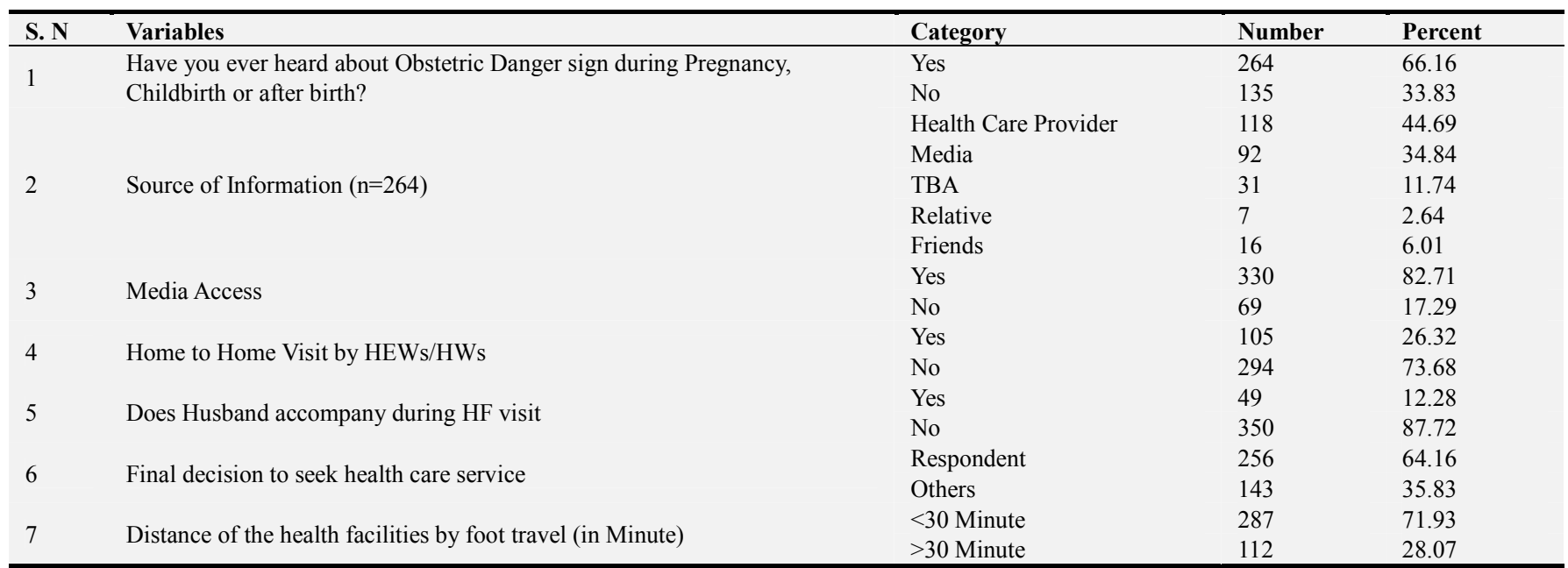

\section{Knowledge of Obstetric Danger Sign}

Out of 399 Respondents, $164(41.11 \%)$ were knowledgeable regarding all type of obstetric danger sign during Pregnancy, Childbirth and Postpartum and 235 $(58.89 \%)$ were not knowledgeable. The most frequently identified obstetric danger sign was sever vaginal bleeding during the pregnancy $64.2 \%$, childbirth $57.4 \%$ and postpartum $50.4 \%$.

Out of 399 Pregnancy women participated in the study only 234 (58.64\%), $205(51.37 \%)$ and 195 (48.87\%) were knowledgeable and mentioned at least two key danger signs during Pregnancy, Childbirth and Postpartum respectively.

Table 6. Frequency distribution of obstetric danger signs-based categories of study participants of Jigjiga City, 2019.

\begin{tabular}{|c|c|c|c|c|c|c|c|}
\hline \multirow{2}{*}{$\begin{array}{l}\text { List of Obstetric Danger signs } \\
\text { Danger Sign }\end{array}$} & \multirow[t]{2}{*}{ Status } & \multicolumn{2}{|c|}{ Pregnancy } & \multicolumn{2}{|c|}{ Postpartum } & \multicolumn{2}{|c|}{ Childbirth } \\
\hline & & $\#$ & $\%$ & $\#$ & $\%$ & $\#$ & $\%$ \\
\hline Sever Vaginal Bleeding & Know & 256 & 64.16 & 201 & 50.38 & 229 & 57.39 \\
\hline Severe Headache & Know & 114 & 28.6 & 96 & 24.1 & 71 & 17.8 \\
\hline Blurred Vision & Know & 185 & 46.37 & 103 & 25.8 & NA & NA \\
\hline Convulsion & Know & 65 & 16.3 & 61 & 15.3 & 94 & 23.6 \\
\hline Swollen Hands and Face & Know & 147 & 36.84 & 91 & 22.8 & NA & NA \\
\hline High Grade Fever & Know & 124 & 31.1 & 114 & 28.57 & 80 & 20.1 \\
\hline Sever Weakness & Know & 82 & 20.6 & 37 & 9.3 & NA & NA \\
\hline
\end{tabular}




\begin{tabular}{|c|c|c|c|c|c|c|c|}
\hline \multirow{2}{*}{$\begin{array}{l}\text { List of Obstetric Danger signs } \\
\text { Danger Sign }\end{array}$} & \multirow[t]{2}{*}{ Status } & \multicolumn{2}{|c|}{ Pregnancy } & \multicolumn{2}{|c|}{ Postpartum } & \multicolumn{2}{|c|}{ Childbirth } \\
\hline & & $\#$ & $\%$ & $\#$ & $\%$ & $\#$ & $\%$ \\
\hline Severe Abdominal Pain & Know & 91 & 22.8 & NA & NA & NA & NA \\
\hline Reduced Fetal Movement & Know & 57 & 14.3 & NA & NA & NA & NA \\
\hline Mentioned membrane rapture & Know & 65 & 16.3 & NA & NA & NA & NA \\
\hline Lack of Consciousness & Know & 51 & NA & 62 & 15.5 & 52 & 13.0 \\
\hline Foul Smelling Vaginal Discharge & Know & NA & NA & 146 & 36.6 & NA & NA \\
\hline Prolonged Labor & Know & NA & NA & NA & NA & 169 & 42.36 \\
\hline Others & Know & 17 & 4.3 & 13 & 3.3 & 11 & 2.8 \\
\hline
\end{tabular}

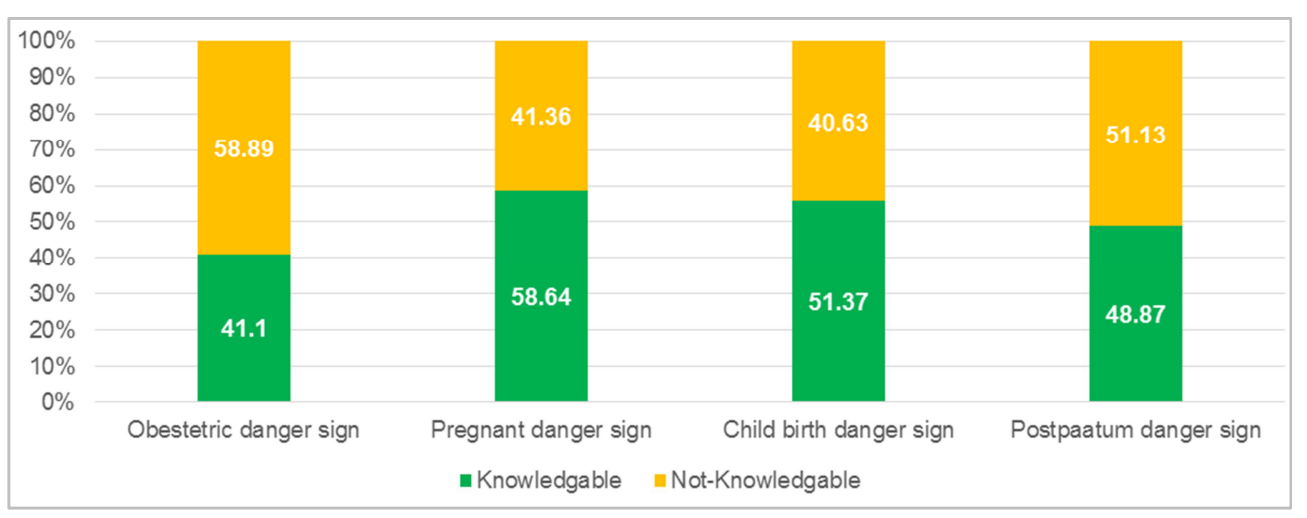

Figure 2. Knowledge of Obstetric danger sign distributed by Categories.

As shown in the below table the most commonly mentioned danger sign during pregnancy were Severe vaginal bleeding 256 (64.16\%) followed by 185 (46.36\%) blurred vision and 147 (36.84\%) Swollen hand and face. Whereas the most frequently identified danger sign during childbirth were vaginal bleeding 229 (57.39\%), Prolonged labor 169 (42.36\%), Retained Placenta 136 (34.09\%) and Convulsion 94 (23.56\%).

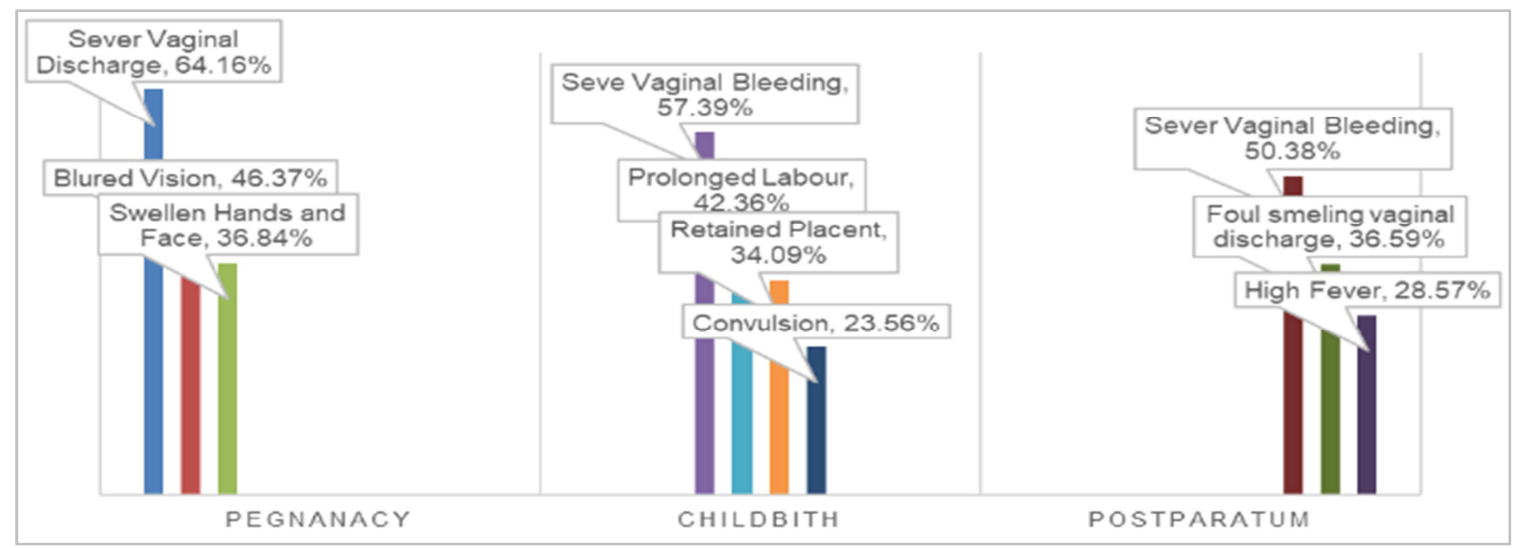

Figure 3. Key Obstetric Danger Sign Distributed by Categories.

In addition to that, the leading danger sign identified during postpartum were 201 (50.38\%) sever vaginal bleeding, $146(36.59 \%)$ Foul smelling vaginal discharge and 114 (28.57\%) high fever.

Factor Associated on Knowledge of Obstetric Danger Sign-Bivariate and Multi-variate Analysis

In the final analysing model, Pregnant women's educational status, Pregnant women's occupational status, Monthly income, gravidity, ANC follow up, PNC follow up, past obstetric history, media access, home to home visit, final decision to seek health care and husband accompany during visit had statistically significant association with the knowledge of obstetric danger sign.
In this study, pregnancy women with formal education had two times [AOR: 2.297, 95\% CI (1.274, 4.143)], higher odds of being knowledgeable on obstetric danger sign when compared to those pregnancy women with non-formal education. Similarly, the Odds ratio of knowledge of obstetrics danger signs had five times among pregnancy women whose are housewife $[\mathrm{AOR}=4.776,95 \%$ CI $(2.552$, 8.938)] than their counter part where as the Odds ratio of women on knowledge of obstetrics danger signs are four times $[\mathrm{AOR}=3.665 ; 95 \%$ CI $(1.456,9.221)]$ among the pregnancy women have monthly income between 500-1000 ETB then those less than 500 ETB.

Pregnancy women who attended ANC and PNC follow up 
were four times [AOR: 4.226; 95\%CI $(2.256,7.918)]$ and Six times $(\mathrm{AOR}=5.256,95 \% \mathrm{CI}(2.879,9.595)]$ were more likely to know obstetric danger signs as compared to their contraparts respectively while the respondents who were pregnancy more than two had three times [AOR: 2.824; 95\%CI (1.193, 6.686)] more likely of knowledgeable toward obstetric danger sign than those respondents who were pregnancy for first time. In addition to that mother with family size more than four are two time [AOR: 2.265 ; 95\%CI $(1.009,5.082)$ ] and respondent's experience of past obstetric danger sign had four times [AOR: 4.273; 95\%CI $(2.042,8.944)]$ then those did not experience past obstetric danger sign.
According to the study, A pregnancy mothers who have mass media access had five times $[\mathrm{AOR}=4.679$, 95\% CI $(2.017,10.855)]$ higher knowledge of obstetric danger signs than those do not have and pregnancy mothers who have home visit made by health care providers had three times $[\mathrm{AOR}=2.554,95 \% \mathrm{CI}(1.321,4.938)]$ higher knowledge of obstetric danger signs than those who do not have home to home visit whereas the pregnancy women whose their husband accompanied during health care service visit had three times [AOR: 3.203; 95\% CI $(1.297,7.909)$ ] higher knowledge of obstetric danger sign than their country part.

Table 7. Bivariate analysis result on factor associated with knowledge of obstetric danger sign of the study participants of Jigjiga City, 2019.

\begin{tabular}{|c|c|c|c|c|c|c|}
\hline \multirow{2}{*}{ No } & \multirow{2}{*}{ Variables } & \multirow{2}{*}{ Category } & \multicolumn{2}{|c|}{ Knowledge of Obstetric Danger Sign } & \multirow{2}{*}{ COR $(95 \%$ of $\mathrm{CI})$} & \multirow{2}{*}{ P-Value } \\
\hline & & & Knowledgeable & Not Knowledgeable & & \\
\hline \multirow{3}{*}{1} & \multirow{3}{*}{ Age of the pregnant Mother } & $<19$ years & 13 & 14 & $1.004(0.45,2.240)$ & 0.992 \\
\hline & & $20-29$ years & 102 & 127 & $0.672(0.292,1.546)$ & $0.188^{*}$ \\
\hline & & $>30$ Years & 50 & 94 & 1 & \\
\hline \multirow{3}{*}{2} & \multirow{3}{*}{ Age of the husband } & $<19$ years & 5 & 3 & $0.783(0.186,3.298)$ & 0.739 \\
\hline & & $20-29$ years & 46 & 59 & $0.661(0.162,2.696)$ & 0.564 \\
\hline & & $>30$ Years & 113 & 173 & 1 & \\
\hline \multirow{2}{*}{3} & \multirow{2}{*}{ Marital Status } & Living together" & 162 & 228 & $2.487(0.510,12.136)$ & 0.260 \\
\hline & & Not Living together ${ }^{\Omega}$ & 2 & 7 & 1 & \\
\hline \multirow{2}{*}{4} & \multirow{2}{*}{ Ethnicity } & Somali & 153 & 211 & $1.582(0.752-3.327)$ & $0.226^{*}$ \\
\hline & & Others $^{*}$ & 11 & 24 & 1 & \\
\hline \multirow{2}{*}{5} & \multirow{2}{*}{ Religion } & Muslim & 154 & 215 & $0.698(0.318,1533)$ & 0.371 \\
\hline & & Christian $^{+}$ & 10 & 20 & 1 & \\
\hline \multirow{2}{*}{6} & \multirow{2}{*}{ Education Mother } & Formal Education & 97 & 89 & $2.375(1.579,3.571)$ & $0.006^{* *}$ \\
\hline & & Non-Formal Edu & 67 & 146 & 1 & \\
\hline \multirow[b]{2}{*}{7} & \multirow[b]{2}{*}{ Education Husband } & Formal Education & 118 & 125 & $2.257(1.474,3.457)$ & $0.053^{*}$ \\
\hline & & Non-Formal Edu & 46 & 110 & 1 & \\
\hline \multirow{2}{*}{8} & & Housewife & 118 & 99 & $3.224(2.112,4.921)$ & $0.001 * * *$ \\
\hline & Occupation Mother & Others" & 46 & 136 & 1 & \\
\hline & & Employed & 122 & 151 & $1.616(1.040,2.510)$ & 0.852 \\
\hline 9 & Occupation Husband & Others $^{\mathrm{E}}$ & 42 & 84 & 1 & \\
\hline & & Less the 3 & 31 & 60 & $1.256(0.745,2.120)$ & 0.837 \\
\hline 10 & Family Size & Between 4 o 6 & 74 & 114 & $1.872(1.067,3.284)$ & $0.047 *$ \\
\hline & & More then 7 & 59 & 61 & 1 & \\
\hline & & $<500$ & 16 & 48 & $2.286(1.102,4.739)$ & $0.100^{*}$ \\
\hline 11 & Monthly family income & $500-1000$ & 32 & 42 & $2.400(1.296,4.445)$ & $0.006 * *$ \\
\hline & & $>1000$ & 116 & 145 & 1 & \\
\hline & & $<1$ & 14 & 48 & $1.821(0.918,3.615)$ & 0.546 \\
\hline 12 & Gravida & between 2 to 4 & 51 & 96 & $3.730(1.928,7.216)$ & $0.018^{*}$ \\
\hline & & $>5$ & 99 & 91 & 1 & \\
\hline & & Yes & 133 & 112 & $4.721(2.953,7.518)$ & $0.000 * * *$ \\
\hline 13 & ANC Visit & No & 31 & 123 & 1 & \\
\hline & & Yes & 101 & 68 & $3.937(2.580,6.007)$ & $0.001 * * *$ \\
\hline 14 & PNC Visit & No & 63 & 167 & 1 & \\
\hline & & Yes & 74 & 62 & $2.294(1.503,3.502)$ & $0.090 *$ \\
\hline 15 & Institution Delivery & No & 90 & 173 & 1 & \\
\hline & History of Obstetric danger & Yes & 46 & 30 & $2.644(1.595,4.448)$ & $0.001 * * *$ \\
\hline 16 & sign & No & 118 & 205 & 1 & \\
\hline & & Accessed & 147 & 183 & $2.457(1.363,4.428)$ & $0.001 * * *$ \\
\hline 17 & Media Access & Not Accessed & 17 & 52 & 1 & \\
\hline 18 & Home to Home Visit by & Yes & 52 & 53 & $1.594(1.017-2.498)$ & $0.005 * *$ \\
\hline 18 & HEWs/HWs & No & 112 & 182 & 1 & \\
\hline 10 & Final decision to seek health & Respondent & 122 & 134 & $2.189(1.416-3.384)$ & $0.001 * * *$ \\
\hline 19 & care service & Others & 42 & 101 & 1 & \\
\hline 20 & Distance to health facilities & $<30$ Minutes & 121 & 166 & $1.170(0.748,1.829)$ & 0.492 \\
\hline 20 & by foot travel (in Minute) & $>30$ Minutes & 43 & 69 & 1 & \\
\hline & Does Husband accompany & Accompanied & 28 & 21 & $2.098(1.145,3.843)$ & $0.012 * *$ \\
\hline 21 & during HF visit & Not Accompanied & 136 & 214 & 1 & \\
\hline
\end{tabular}

* significant association at p-value $<0.25, * *$ significant association at p-value $<0.01, * * *$ significant association at p-value $<0.001$.

$\approx$ Government Employee, Merchants, Private employee ${ }^{\mathfrak{f}}$ Merchants, daily labors, others. 
Table 8. Multivariate analysis result on factor associated with knowledge of obstetric danger sign of the study participants of Jigjiga City, 2019.

\begin{tabular}{|c|c|c|c|c|c|}
\hline No & Variables & Category & COR $(95 \%$ of $C I)$ & AOR $(95 \%$ of CI) & P-Value \\
\hline \multirow{3}{*}{1} & \multirow{3}{*}{ Age of Mother } & $<19$ years & $1.004(0.45,2.240)$ & $0.787(0.253,2.449)$ & 0.679 \\
\hline & & $20-29$ years & $0.672(0.292,1.546)$ & $0.613(0.188,1.992)$ & 0.415 \\
\hline & & $>30$ Years & 1 & 1 & \\
\hline \multirow{2}{*}{2} & \multirow{2}{*}{ Ethnicity } & Somali & $1.582(0.752-3.327)$ & $2.36(0.809,6.885)$ & 0.116 \\
\hline & & Others $^{*}$ & 1 & 1 & \\
\hline \multirow{2}{*}{3} & \multirow{2}{*}{ Education Mother } & Formal Education & $2.375(1.579,3.571)$ & $2.297(1.274,4.143)$ & $0.006 * *$ \\
\hline & & Non-Formal Edu & 1 & 1 & \\
\hline \multirow{2}{*}{4} & \multirow{2}{*}{ Education Husband } & Formal Education & $2.257(1.474,3.457)$ & $1.827(0.992,3.364)$ & $0.053 *$ \\
\hline & & Non-Formal Edu & 1 & 1 & \\
\hline \multirow{2}{*}{5} & \multirow{2}{*}{ Occupation Mother } & Housewife & $3.224(2.112,4.921)$ & $4.776(2.552,8.938)$ & $0.001 * * *$ \\
\hline & & Others" & 1 & 1 & \\
\hline \multirow{2}{*}{6} & \multirow{2}{*}{ Occupation Husband } & Employed & $1.616(1.040,2.510)$ & $1.062(0.566,1.990)$ & 0.852 \\
\hline & & Others ${ }^{\mathcal{E}}$ & 1 & & \\
\hline \multirow{3}{*}{7} & \multirow{3}{*}{ Family Size } & Less the 3 & $1.256(0.745,2.120)$ & $1.081(0.515,2.266)$ & 0.837 \\
\hline & & Between 4 o 6 & $1.872(1.067,3.284)$ & $2.265(1.009,5.082)$ & $0.047 *$ \\
\hline & & More then 7 & 1 & 1 & \\
\hline \multirow{3}{*}{8} & \multirow{3}{*}{ Monthly family income } & $<500$ & $2.286(1.102,4.739)$ & $2.365(0.847,6.599)$ & 0.100 \\
\hline & & $500-1000$ & $2.400(1.296,4.445)$ & $3.665(1.456,9.221)$ & $0.006 * *$ \\
\hline & & $>1000$ & 1 & 1 & \\
\hline \multirow{3}{*}{9} & \multirow{3}{*}{ Gravida } & $<1$ & $1.821(0.918,3.615)$ & $1.322(0.535,3.267)$ & 0.546 \\
\hline & & between 2 to 4 & $3.730(1.928,7.216)$ & $2.824(1.193,6686)$ & $0.018^{*}$ \\
\hline & & $>5$ & 1 & 1 & \\
\hline \multirow{2}{*}{10} & \multirow{2}{*}{ ANC Visit } & Yes & $4.721(2.953,7.518)$ & $4.226(2.256,7.918)$ & $0.000 * * *$ \\
\hline & & No & 1 & 1 & \\
\hline \multirow{2}{*}{11} & \multirow{2}{*}{ PNC Visit } & Yes & $3.937(2.580,6.007)$ & $5.256(2.879,9.595)$ & $0.001 * * *$ \\
\hline & & No & 1 & 1 & \\
\hline \multirow{2}{*}{12} & \multirow{2}{*}{ Institution Delivery } & Yes & $2.294(1.503,3.502)$ & $1.715(0.920,3.195)$ & 0.090 \\
\hline & & No & 1 & 1 & \\
\hline \multirow{2}{*}{13} & \multirow{2}{*}{ History of Obstetric danger sign } & Yes & $2.644(1.595,4.448)$ & $4.273(2.042,8.944)$ & $0.001 * * *$ \\
\hline & & No & 1 & & \\
\hline \multirow{2}{*}{14} & Media Accecs & Accessed & $2.457(1.363,4.428)$ & $4.679(2.017,10.855)$ & $0.001 * * *$ \\
\hline & Miedia Access & Not Accessed & 1 & & \\
\hline 15 & Home to Home Vicit by HFWs/HWs & Yes & $1.594(1.017-2.498)$ & $2.554(1.321,4.938)$ & $0.005 * *$ \\
\hline 15 & Home to Home Visit by HEWS/HWs & No & 1 & & \\
\hline 16 & Final decision to seek health care service & Respondent & $2.189(1.416-3.384)$ & $1.777(0.971,3.254)$ & $0.001 * *$ \\
\hline 10 & rinal decision to seek neaim care service & Others & 1 & & \\
\hline 17 & Does Hushand accomnany during HF vicit & Accompanied & $2.098(1.145,3.843)$ & $3.203(1.297,7.909)$ & $0.012 * *$ \\
\hline 17 & Does Husband accompany aurmg HF Visit & Not Accompanied & 1 & 1.000 & \\
\hline
\end{tabular}

* significant association at $\mathrm{p}$-value $<0.05, * *$ significant association at $\mathrm{p}$-value $<0.01, * * *$ significant association at $\mathrm{p}$-value $<0.001$.

$\approx$ Government Employee, Merchants, Private employee ${ }^{£}$ Merchants, daily labors, others.

\section{Discussion}

In this study, knowledge of obstetric danger sign among the pregnant women attending ANC clinic in Jigjiga city public health institution were $41.1 \%$. The finding of this study is comparable to the studies conducted in some parts of Ethiopia; $37.9 \%$ in Jigjiga town, Somali region, Ethiopia, 2018 [20] and 37.9\% in Behardahar, Ethiopia, 2019 [28]; and higher than other studies, $24.1 \%$ in Arbaminnji, Ethiopia, 2014 [31], 25.2\% in Chamwino district, Tanzania, 2014 [9]; and $15.5 \%$ in Erar, Somali region, Ethiopia, 2016 [19]. This study is also lower than the findings of other part of the country and African countries like 50.6\% in Debre Berhan town, Ethiopia, 2019 [32]; 77.1\% in Murtala Muhumed specialist hospital, kano, Nigeria [33] and other Asian countries, 90.2\% in Dhaka, Bangladesh, 2019 [34].

Similarly, the level of knowledge of obstetrics danger signs that occur during pregnancy, childbirth and postpartum in study indicated 234 (58.64\%), 205 (51.37\%) and 195
(48.87\%) respectively. this finding is higher than the study conducted in Goba, Ethiopia, 2015, 31.9\% during pregnancy, $27 \%$ during child birth and $22.1 \%$ during postpartum period [35]; Debra Berhan Town, Central Ethiopia, 2015, in 38.6\% were knowledgeable danger sign during pregnancy [36]; in Rayo Koba, North Walo Zone, Ethiopia, 2017, About 46.7\%, $27.8 \%$, and $26.4 \%$ of the mothers were knowledgeable about obstetric danger signs during pregnancy, delivery, and postpartum period respectively [6]; and lower than study conducted in some part of Africa, in Northern, Nigeria around $63.7 \%, 71.7 \%$ \& $53.9 \%$ in Kaduna and $42.4 \%, 62.1 \%$ \& $34.9 \%$ in katsina were knowledgeable about obstetric danger signs during pregnancy, delivery, and postpartum period respectively [37]; and in Rural Madagascar, 2018, Knowledge of at least know one danger sign $80.9 \%$ at pregnancy at $51.9 \%$ at childbirth and $50.8 \%$ at postpartum [22].

This study is constant to the study conducted in Dilla University, Ethiopia, on $58 \%, 51 \%$ and, $145 \%$ of mother 
were knowledgeable for obstetric danger sign occur during pregnancy, at child birth and post-partum period respectively [16]; The possible reasons of variation among research may be due to study design and type, operational definition of obstetric danger signs and logical parameters used, Geographic location, Time variations.

According to this study, Pregnancy mother with formal education have a two times [AOR: 2.297, 95\% CI (1.274, 4.143)] statistically significance association with knowledge of obstetric danger sign then the pregnancy women with no formal education, this study is similarly to the study conducted in Jigjiga city, Somali region, 2018, [20]; Debre Burhan city administration, north Shewa zone, Ethiopia, 2014 [29]; in Debru Berhan city administration, Ethiopia, 2015 [36]; in Al-nawariah primary health care center, Makkah al-mukarramah, Saudi Arabia, [24]; as well as a cross sectional study conducted in Chamwino distract, Tanzania, 2017, [9]; This might be due to the fact that education on pregnancy women and her husband provides appropriate information about the danger signs and they are better knowledge to recognize danger sign of obstetrics.

Based on this study, it was found that the pregnant women's occupation was significantly associated with knowledge of obstetric danger signs and it has five [AOR $=4.776,95 \%$ CI $(2.552,8.938)]$ knowledgeable than their counterpart. It is similar to the study done in Rayo Koba, North Walo Zone, Ethiopia, 2017 [6]; in Mekelle City, Tigray, Ethiopia, 2014, [38]; that founded women's occupation appeared to be factor associated with knowledge of obstetric danger sign. However, this finding is contrasted with cross sectional study done in Chamwino distract, Tanzania, 2017, [9]; This may be due to the having better opportunity for discussion, to gain and share experiences with others in working environment so that women in the home are less exposure then those meet with others.

The obstetric characteristic of the pregnancy women emerged as a determinant factor of the level of women's knowledge on obstetric danger signs. As per this study, The pregnancy women who visited health facility for ANC has as significant association with knowledge of obstetric danger sign with four times [AOR: 4.226; 95\%CI $(2.256,7.918)$ ], This is congruent to the study done in Debark town, north west Ethiopia, 2014, [39]; in Erar distract, Somali region of Ethiopia, 2014, [19]; in Debaytilatgin district, Ethiopia, 2015, [40]; and in Afar Regional State, Ethiopia, 2019, [41]; This indicate that those pregnant women who are in touch with health personnel in ANC visit have knowledgeable about obstetric danger signs.

Pregnancy women who attended PNC follow up were Six times $(\mathrm{AOR}=5.256,95 \% \mathrm{CI}(2.879,9.595)]$ more likely to know obstetric danger signs as compared to their contra-parts This could be due to the health education given after delivery with the skilled and trained birth attendant. Currently the Ethiopian government focuses on controlling the Home delivery and expanding the urban and rural health extension practitioners due improving the knowledge of pregnant mothers on the danger signs of pregnancy.
In this study, Mother's gravidity more than two were identified to be a significant associated with knowledge of obstetric danger signs had three [AOR: 2.824 ; 95\%CI (1.193, 6.686)] more likely of knowledgeable toward obstetric danger sign than those respondents who were pregnancy for first time. A similar study conducted in Erar distract, Somali region of Ethiopia revealed that gravida more than five were Seven times [AOR: 6.65, 95\% CI $(2.48,17.89)$ ] than those respondents who were pregnancy for first time [19]; Other studies conducted in Afar, Oromia in Debre berhan town, north Shoa, Oromia, Ethiopia, and Tigre region of Ethiopia also showed significant association between increasing mother's gravidity. Whereas mother with family size more than four are two time [AOR: 2.265; 95\%CI $(1.009,5.082)$ ] are more knowledgeable then those below three members. For better explanation on this, the issues and history of number or repeated pregnancies can increase the knowledge about danger signs of pregnancy it might be due to the increased health institution contact and information gained from the previous experiences.

The result of the present study also stated that mass media exposure has statistically significant association with knowledge of obstetric danger sign, The likelihood of being knowledgeable about the danger signs of pregnancy, labor and childbirth were five times [AOR: $4.961,95 \%$ CI $(2.182$, 11.280)] higher for mothers who had accessed media the it's contra part. This is line with the community based crosssectional study conducted in Tsegedie District, Tigray, Ethiopia, 2013/14, [42]. This can further be explained by the fact that mass media is effective in information dissemination, which increases awareness about health care information and health care facilities that are available and fosters interpersonal communication, which could facilitate behavioural changes.

In this study, pregnancy mother's experience of past obstetric danger sign had a four times [AOR: 4.273 ; 95\% CI $(2.042,8.944)]$ knowledgeable on obstetric danger sign than those who do not have past obstetric danger sign, other study conducted in Al-nawariah primary health care centre, Makkah al-mukarramah, Saudi Arabia [24] was found to be independent predictors of knowledge of women about danger signs because of several experiences indicate the need for giving more attention to indicate and easily recognize the obstetric danger sign.

In this study, Monthly income between 500-1000 ETB of among the pregnancy women have four times $[\mathrm{AOR}=3.665$; $95 \%$ CI $(1.456,9.221)]$ knowledgeable on of obstetric danger signs than those less the 500 ETB. It is in line with the study conducted by Yinager et al. in Arbanminch, Ethiopia showed a Monthly income had been an important predictor of knowledge on obstetric danger signs. Mothers who earned 500 Ethiopian birr and above were 2 times more likely to have knowledge on obstetric danger signs [31]. The similar study in Debra Burhan, Ethiopia during 2014 presented that monthly income had significant association with obstetric danger signs knowledge that participants who had monthly income more than or equal to 1000 had 3.3 times good 
knowledge than respondents who had monthly income less than 1000 [29]. Another study in Goba District, Ethiopia [19] and Chamwino district, Tanzania [9] indicated employed women were more likely to be knowledgeable about obstetric danger signs compared to unemployed women. This could be because women who earn their own salaries might be more autonomous when seeking better health care compared to unemployed women.

Although other researcher did not focused the predictor of husband accompanied during visit on relation to knowledge of obstetric danger sign, this study clearly indicated that pregnancy women that their husband accompanied during health care service visits were a highly associated, three times [AOR: $3.340 ; 95 \% \mathrm{CI}(1.374,8.120)$ ] with knowledge of the pregnant mothers about obstetric danger signs than those their husband did not accompanied during health care service visit. Related study on that indicated pregnant women who were accompanied by their spouses during antenatal visits were about 1.7 times more likely to prepare for childbirth compared to those who were not. It is because men's' involvement in antenatal care or other basic services increases the likelihood that men will be taught about knowledge of obstetric danger of birth preparedness which increases the likelihood that men will support their wives.

\section{Conclusions and Recommendations}

\section{Conclusion}

This study finding indicated that knowledge of obstetric danger signs is poor due to the lack of education of health mother and husband, health care service utilization as well as other family influence on decision to seek care and husband accompanies. Only $41.1 \%$ of the pregnancy women had knowledgeable about danger signs. Having exposure to health care service like ANC, PNC and Institutional delivery was found slightly significantly associated with knowledge of obstetric danger signs. The mostly commonly danger sign mentioned were severe vaginal bleeding, blurred vision, swollen hand \& face, Foul Smelling Vaginal Discharge.

\section{Recommendation}

The following are the recommendation from the findings of this study:

1. Regional health buraus shall have to provide and distribute IEC/BCC materials including pamphlets, posters, magazines and books and develop IEC/BCC strategy based in Somali region context that help women, families and communities on their knowledge and awareness towards obstetric danger signs.

2. Since, there is a lower level knowledge of obstetric danger sign among the respondents, advocacy to skill up health care providers on community mobilisation and health education topics on knowledge obstetric of danger signs is highly recommended.

3. Improving and opening environment for husband to support women's health seeking behaviour and allowing husband to accompany women's during health care service visit and promoting home visit by HEW/HWs which can increase early recognition of danger signs and their timely health seeking behaviour.

4. Health education and community mobilization strategy to support front line staff and provide IEC/BCC activities at health facility and community level and the channel of health education should be considered through media and health care providers which our study shows high magnitude and association on knowledge of obstetric danger sign.

5. Ensure women empowerment and Inclusive education like Female school enrolment, RH club and Mother to mother support group in the discussion of experience sharing and awareness raising towards obstetrics danger sign with the mother experienced or have past obstetric complication.

6. Conduct advocate meeting from the regional level throughout the community level on the discussion of early identification of pregnancy danger sign to access Basic obstetric care service and uptake of Mother waiting home and strength bi-directional referral system between health facilities and communities.

7. Interventions targeting improvement of maternal health should consider the quality of $\mathrm{RMNCH}$, including the quality of information offered to pregnant women and the community at large, especially on obstetric danger signs.

8. Awareness creation of the key danger signs needs to be given priority as it ensures birth preparedness and complication readiness.

9. Health education given to pregnant women should not be only through routine antenatal care, but also through the Mass Medias, pregnancy women conference, drama show and home visit during pre or post conception period.

\section{References}

[1] WHO. Mother-baby package: Implementing safe motherhood in countries. 1994.

[2] Federal Democratic Republic of Ethiopia MoH. Management protocol on selected of Seclected Obestetric Topics; 2010.

[3] JHPIEGO. Monitoring birth preparedness and complication readiness. Tools and indicators for maternal and newborn health; 2004.

[4] Haile HGSBN. Awareness of Danger Signs of Pregnancy and its Associated Factors among Pregnant Women who Visit ANC in Mekelle Public Hospitals. 2014.

[5] Andrea B Pembe DPUACGLLNaED. Rural Tanzanian Women's Awareness of Danger Signs of Obstetric Complications. 2012.

[6] Mulatu NBaT. Knowledge of obstetric danger signs and associated factors among reproductive age women. 2017.

[7] WHO. Standards for Maternal and Neonatal Care: Birth and Emergency Preparedness in Antenatal Care: Department of Making Pregnancy Safer Geneva; 2006. 
[8] The federal democratic republic of Ethiopia $\mathrm{MoH}$. Hsector transformation plan (HSTP). Addis Ababa: Minstry of Health (MOH). Addisababa:; 2015.

[9] Deogratius Bintabara RNMMaAAM. Knowledge of obstetric danger signs among recently-delivered women in Chamwino district, Tanzania: across-sectional study. 2017.

[10] UNICEF, UNFPA, Bank W. Trends in maternal mortality: 1990-2015. 2016.

[11] Fund UNC. The state of the world's children 2016 a fair chance for every child. New York (NY):. 2016.

[12] WHO. WHO. Trends in maternal mortality 1990-2010. Geneva:. 2012.

[13] Alkema L, CD, HD, ZS, MAB. Global, regional, and national levels and trends in maternal mortality between 1990 and 2015, with scenario-based projections to 2030. 2016.

[14] FMOH. Health sector transformation plan (HSTP): Ethiopia Minstry of Health (MOH). In. Addis Ababa; 2015.

[15] ECSA. Ethiopia demographic and health survey. 2016.

[16] Mwilike B, NG, KM, MK, ML, \& HS. Knowledge of danger signs during pregnancy and subsequent healthcare seeking actions among women in Urban Tanzania: a cross -sectional study. 2018.

[17] Tadele Girum MS. Knowledge about Obstetric Danger Signs and Associated Factors among Antenatal Care Attendants. March 2017; 6 .

[18] Samuel Dessu GGaAT. Assessment of Knowledge on Danger Sign of Pregnancy and Associated Factors among ANC Attendant Pregnant women. 2018; 8 (1).

[19] Roman BR, Roman BR, Patel SG, Wang MB, Pou AM, Holsinger FC, et al. Guideline Familiarity Predicts Variation in Self-Reported Use of Routine Surveillance PET/CT by Physicians Who Treat Head and Neck Cancer. Journal of The National Comprehensive Cancer Network. 2015; 13 (1): p. 69 77.

[20] Nebiyu Maseresha KWaLD. Knowledge of obstetric danger signs and associated factors among pregnant women. 2016.

[21] Haile S. Knowledge about Obstetric Danger Signs and Associated Factors among Pregnant Mothers in Jigjiga City, Somali Regional State, Eastern, Ethiopia: A Community based cross-sectional study. May 2018.

[22] WHO. World Health Organisation. [Online].; 2018 [cited 2019 Available http://apps.who.int/iris/bitstream/10665/250796/1/.

[23] Ania Salem OLSSJHACB. Cross-sectional survey of knowledge of obstetric danger signs among women. 2018.

[24] Bardisi DAKaSM. KNOWLEDDGE AND FACTORS ASSOCIATED WITH OBSTETRIC DANGER SIGNS AMONG PREGNANT WOMEN. 2016.

[25] UN Minunim Development Goals M. http://www.un.org/millenniumgoals/maternal.shtml. 2016.
[26] Yewondwossen Bitew WoAaSC. Birth Preparedness and Complication Readiness Practice and Associated Factors among Pregnant Women, Northwest Ethiopia. 2016.

[27] Saaka M APAMMA. The effect of social behavior change communication package on maternal knowledge in obstetric danger signs among mothers in East Mamprusi District of Ghana. Globalization and Health. 2017.

[28] Azezu Asres Nigussie1* AAEYMDaEAM. Factors associated with knowledge on obstetric danger signs among women who gave birth within 1 year. 2019.

[29] Sodere Nurgi ET. assessment of KAP of obstetric danger signs during pregnancy among mothers in debre birhan city administration, north shewa zone, amhara, ethiopia. 2014.

[30] BELDA SS. Birth Preparedness, Complication Readiness And Other Determinants Of Place Of Delivery; The Case Of Goba Wereda, Bale Zone, South East Ethiopia. 2016.

[31] Yinager Workineh DHTGNDMMMS, MMG. Knowledge of Obstetric Danger Signs and its Associated Factors. 2014.

[32] Berhanu Negese SHBW. knowledge, risk perception about obstetric danger signs and associate factors among mothers. 2019.

[33] Ayyuba Rabiu 1HIL. Knowledge of obstetric danger signs among pregnant women attending antenatal clinic in kano, Nigeria. 2019.

[34] Khanom H, HMT, BS, SN, KSB, KF, KS, BPC, HS. Assessment of Level of Knowledge and Attitude on Danger Signs Among the Mul-tipara Pregnant Mothers Attending for ANC in Gynae Out Patient Department. 2019.

[35] Daniel Bogale Dm. Knowledge of obstetric danger signs among child bearing age women in Goba district, Ethiopia. 2015.

[36] Abayneh Akililu Solomon NWAEACMBB. Knowledge About Danger Signs of Pregnancy and Associated Factors Among Pregnant Women in Debra Birhan Town, Centeral Ethiopia. Science Journal of Public Health. 2015;: p. 269-273.

[37] Olugbenga Oguntunde1 JNFMYDSDASaIS. Factors associated with knowledge of obstetric danger signs and perceptions of the need for obstetric care among married men in northern Nigeria: a cross-sectional survey. 2019.

[38] Tirsit Abiyot1 MKBK. Awareness Of Obstetric Danger Signs And Its Associated Factors Among Pregnant Women. 2014.

[39] Endalamaw M HT. The level of awareness on danger signs of pregnancy and associated factors among ANC attendant pregnant women. 2014.

[40] Dile M TDGMAT. Knowledge of obestetric danger signs and its associated factors. 2015.

[41] Misgan Legesse Liben1* AGWaNBZ. Knowledge of pregnancy danger signs and associated factors among pastoral women. 2019.

[42] Hailu D, Berhe H, Knowledge about Obstetric Danger Signs and Associated Factors among Mothers. 2014. 